\title{
A política internacional dos direitos humanos e o tráfico internacional de mulheres
}

The international policy of human rights and women'sinternational trafficking

\section{Isabela Souza Alcantara ${ }^{1}$}

RESUMO: O propósito desse artigo é analisar a política internacional dos direitos humanos das mulheres, a luz da teoria dos regimes internacionais, e sua relação com o tráfico internacional de mulheres em perspectiva histórica, destacando os instrumentos internacionais que tratam de questões relacionadas à defesa dos direitos humanos das mulheres e ao tráfico internacional de pessoas. A metodologia utilizada para a produção do artigo quanto à abordagem foi qualitativa e quanto ao procedimento foi do tipo bibliográfica, realizada através do levantamento de referências teóricas, feito por meio de livros e artigos científicos, bem como através da análise de publicações especializadas $e$ dados oficiais. Conclui-se que o Brasil tem dado importância à questão do enfrentamento às violações dos direitos humanos das mulheres, através da construção de sistema de apoio para confrontar problemas relacionados às desigualdades de gênero por meio de sua inserção em regimes internacionais. Entretanto, ainda persiste na cultura brasileira uma ótica sexista, discriminações com relação à mulher e violações de seus direitos humanos. Logo, os ganhos internacionais e constitucionais legais de forma isolada não geram automaticamente mudanças sociais e culturais, apesar de denotarem maior segurança para os sujeitos de direito.

Palavras - chave: tráfico internacional de mulheres; direitos humanos; Regimes Internacionais.

ABSTRACT: The purpose of this article is to analyze the international politics of women's human rights, based on the theory of international regimes, and its relation to the women international trafficking in historical perspective, highlighting the international instruments that deal with issues related to the defense of the human rights of women and humans international trafficking. The methodology used for the production of the article concerning the approach was qualitative, and the procedure was the bibliographic type carried out through the collection of theoretical references, made through books and scientific articles, as well as through the analysis of specialized publications and official data. It is concluded that Brazil has given importance to the issue of fighting against the violations of the human rights of women through the construction of a support system to confront problems related to gender inequalities by means of its insertion in international regimes. However, there is still a sexist perspective in Brazilian culture, discrimination against women and violations of their human rights. Therefore, international and constitutional legal isolated gains do not automatically generate social and cultural changes, even though they denote greater security for the subjects of law.

\footnotetext{
${ }^{1}$ Mestre em Relações Internacionais, Universidade Federal da Bahia, Salvador, Brasil.
} 
Keywords: international trafficking in women; human rights; International Regimes.

\section{INTRODUÇÃo}

A ideia de que existe um conjunto de direitos inalienáveis que todos os seres humanos possuem pelo simples fato de ser humano esteve presente em diversos momentos da história. Essa ideia ganhou força após o fim da Segunda Guerra Mundial, especialmente porque, após esse conflito, a necessidade de o indivíduo ser reconhecido como cidadão no cenário internacional se tornou mais evidente (PIOVESAN, 2015).

0 reconhecimento dos direitos humanos das mulheres insere-se nesse contexto. Como primeiro marco legal internacional desse reconhecimento, foi aprovada, em 1979, a Convenção para Eliminação de todas as Formas de Discriminação contra a Mulher no âmbito das Nações Unidas. Além dessa convenção, em 1995, foi aprovada a Convenção Interamericana para prevenir, punir e erradicar a Violência Contra a Mulher, que foi o primeiro tratado internacional de direitos humanos a abordar especificamente a questão da violência contra a mulher (GONÇALVES,2013).

Apesar de todos esses avanços, ainda existe uma variedade de fenômenos que envolvem violações de direitos humanos, como o tráfico internacional de pessoas. 0 tráfico internacional de seres humanos tornou-se uma prática frequente, sendo considerada uma das atividades mais rentáveis do crime organizado internacional na atualidade (UNODC, 2016).

O principal instrumento legal internacional que trata do tráfico internacional de pessoas foi elaborado durante a Convenção das Nações Unidas contra o Crime Organizado Transacional. Também conhecido como Convenção de Palermo, ele foi aprovado pela Assembleia Geral da ONU em 15 de novembro de 2000 e possui três protocolos adicionais, entre eles: o Protocolo Adicional à Convenção das Nações Unidas contra o Crime Organizado Transacional relativo à Prevenção, Repressão e Punição do Tráfico de Pessoas, em especial Mulheres e Crianças. Esse protocolo foi recepcionado pela legislação brasileira no ano de 2004, através do Decreto no 5.017 , que traz no seu art.3ํa a definição mais utilizada para conceituar tráfico internacional de pessoas. ${ }^{2}$

\footnotetext{
${ }^{2}$ Art. 3o - A expressão 'tráfico de pessoas' significa o recrutamento, o transporte, a transferência, o alojamento ou o acolhimento de pessoas, recorrendo à ameaça ou uso da força ou a outras formas de coação, ao rapto, à fraude, ao engano, ao abuso de autoridade ou à situação de vulnerabilidade ou à entrega ou 
A questão de gênero, para o tráfico internacional de pessoas, torna-se uma das mais relevantes, visto que as estatísticas demonstram que a grande maioria das vítimas é do sexo feminino. Mulheres de todo o mundo são culturalmente, socialmente, economicamente, politicamente e legalmente desfavorecidas em relação aos homens. Essa inferioridade pode ser observada em diferentes níveis sociais: o familiar, o local, o nacional, o regional e o internacional (USMAN, 2014).

A maior parte das pessoas vítimas de tráfico, no Brasil e no mundo, são mulheres e são utilizadas para fins de exploração sexual. Segundo Relatório da Organização Internacional do Trabalho (OIT), 43\% das pessoas traficadas no mundo são vítimas de exploração sexual, 32\% são vítimas de exploração econômica e 25\% são vítimas de outros tipos de exploração (OIT, 2005, p.15). Ou seja, a maior parte das pessoas traficadas no mundo sofre exploração de seus corpos para satisfazer intensões sexuais de outras pessoas.

Ademais, a OIT traz outro dado relevante em relação às vítimas de tráfico: das vítimas de exploração econômica, $56 \%$ são mulheres e meninas; das vítimas de exploração comercial sexual, 98\% das vítimas são mulheres e meninas (OIT, 2005, p.16).

Em relação ao Brasil, o tráfico internacional de pessoas e a questão migratória estão em evidência na atualidade. Hoje, nosso país é considerado um país de origem, de trânsito e de destino de pessoas traficadas. Os relatórios mais recentes sobre tráfico, elaborados pelo Ministério da Justiça em parceria com o Escritório das Nações Unidas sobre Drogas e Crimes, revelaram que o fenômeno vem se mantendo em expansão, principalmente no que se refere às mulheres, não obstante os avanços alcançados com as medidas de enfrentamento adotadas até então (MINISTÉRIO PÚBLICO FEDERAL, 2016).

Trata-se de um fenômeno que não está relacionado apenas com os Estados nacionais no papel de provedores de segurança, mas, sobretudo, relaciona-se com a segurança humana para além das fronteiras estatais. Assim, ameaça tanto a ordem interna dos Estados nacionais quanto o próprio sistema internacional, uma vez que afeta a proteção dos direitos humanos, bem como interfere em questões envolvendo tratados

aceitação de pagamentos ou benefícios para obter o consentimento de uma pessoa que tenha autoridade sobre outra para fins de exploração. A exploração incluirá, no mínimo, a exploração da prostituição de outrem ou outras formas de exploração sexual, o trabalho ou serviços forçados, escravatura ou práticas similares à escravatura, a servidão ou a remoção de órgãos. [...] 
internacionais, política externa e soberania. Portanto, discutir a política internacional dos direitos humanos a partir da teoria dos regimes internacionais é fundamental para entender como o Brasil se comporta diante desse contexto.

\section{A CONSTRUÇÃo DOS REGIMES INTERNACIONAIS NA TEORIA DAS RELAÇÕES INTERNACIONAIS}

O sistema internacional, a partir da década de 1970, não se configurava mais como um mero sistema de Estados unitários interagindo entre si, e sim como uma série de agentes interagindo através de redes e baseando-se em regras que sustentavam o sistema mundial. A ampla gama de atores interagindo permitiu maior difusão da distribuição de poder e maior transparência das relações.

Nesse contexto de transição e reordenamento, o realismo começava a perder força como corrente explicativa das relações internacionais e surge uma nova corrente teórica expondo que os Estados eram capazes de cooperar a despeito de distribuições assimétricas de poder. Essa corrente teórica era o Liberalismo, que teve como uma de suas teorias mais conhecidas a Teoria da Interdependência Complexa elaborada por Robert Keohane e Joseph Nye, em trabalho publicado no ano 1977.

Segundo essa teoria, entende-se que o cenário político internacional abarca agentes estatais e não estatais, não havendo hierarquia entre eles e as relações assimétricas de poder nem sempre implicam em uso efetivo e instrumental de força. Como a política internacional é considerada anárquica, a formação de regimes internacionais é colocada como uma tentativa de se estabelecer a ordem a partir da conjugação das atividades dos Estados e das organizações internacionais (KEOHANE; NYE, 1997).

0 mundo visto a partir da interdependência complexa, não leva, entretanto, à ausência de conflitos. Nesse sentido, as organizações internacionais, como atores não estatais, desempenham o papel de intermediadoras das negociações e exercem estímulo, através de mecanismos específicos, à cooperação. A interdependência afeta o comportamento dos Estados, da mesma forma que ações de governos também influenciam os moldes da interdependência. Regulando e controlando as relações 
interestatais, os governos criam e aceitam regras e instituições. 0 conjunto de arranjos estatais que afetam as relações de interdependência Keohane e Nye (1997) são chamados de regimes internacionais.

De acordo com esses autores, os acontecimentos ocorridos em determinado país podem ocasionar consequências em outros países, sem que eles tenham qualquer controle sobre esses fatos e seus efeitos. A partir da elaboração da teoria da interdependência complexa foi possível embasar os estudos dos regimes internacionais, trazendo à luz outros conceitos como cooperação e instituições internacionais e articulando esses conceitos de modo a compreender qual seria o real papel das instituições internacionais na promoção da cooperação e como esses elementos explicam as relações internacionais na nova ordem que se desenhava (KEOHANE; NYE, 1997).

Assim, a existência de interesses comuns aliada à racionalidade dos atores produziria, em determinado contexto, regimes internacionais de cooperação mútua, tendo as instituições internacionais papel importante no que diz respeito à capacidade de induzir os atores à cooperação. Em síntese, "os regimes facilitam a cooperação, propiciando regras, normas, princípios e procedimentos que auxiliam os agentes a superar barreiras à cooperação identificadas pelas teorias econômicas como falha de mercado" (KEOHANE, 1984, p.96, tradução nossa).

De acordo com a perspectiva liberal, a cooperação deve ser entendida através da ação política coordenada de agentes com o objetivo de gerar uma conformidade de atos para atingir determinados objetivos individuais. A avaliação da eficácia de um projeto de cooperação, portanto, deve ser realizada por intermédio da comparação dos resultados obtidos com sua execução em relação aos que seriam alcançados em sua ausência. Se o resultado final for a melhora da situação dos agentes envolvidos neste processo, o ato de cooperação pode ser considerado eficaz. (KEOHANE, 1989).

Para entender o funcionamento do processo de cooperação internacional, é preciso ter em mente o conceito de instituições internacionais, uma vez que esta prática sempre ocorre em um contexto institucional. A definição de instituições internacionais elaborada por Keohane (1989) se baseia na ideia de existência de um conjunto de regras duráveis que prescrevem comportamentos, constrangem a atividade e moldam as expectativas dos atores, delimitando o papel que cada um de seus membros deve desempenhar. As instituições, portanto, podem ser: um padrão geral de comportamento, 
como os regimes internacionais; ou um arranjo específico formal ou informal, sendo, neste caso, identificáveis no tempo e no espaço e dependentes da decisão de seus membros, como as organizações internacionais (KEOHANE, 1989).

Os adeptos dessa abordagem, assim, acreditam que os atores internacionais, mesmo vivendo em um ambiente anárquico e de autoajuda, são capazes de desenvolver relações cooperativas e mutuamente benéficas, ainda que não exista uma autoridade supranacional com poderes para forçar o cumprimento de normas.

De forma complementar aos autores supracitados, o conceito de Regimes Internacionais elaborado por Stephen Krasner (2012) aduz que podem ser conceituados como "princípios, normas, regras e procedimentos de tomada de decisões de determinada área das relações internacionais, em torno dos quais convergem as expectativas dos atores." (KRASNER, 2012, p.185).

Esse autor, apesar de ser realista do ponto de vista teórico, desenvolve um importante conceito de regimes internacionais baseando-se em dois elementos centrais: os princípios e as normas. Keohane e Nye (1977) também trazem esses elementos ao conceituarem regimes como "redes de regras, normas e procedimentos que regulam comportamento dos atores e controlam seus efeitos." (1977, p.19). Entretanto, Krasner (1985) apresenta uma percepção mais detalhada sobre cada um deles.

É fundamental, portanto, estabelecer a diferença entre princípios e normas, regras e procedimentos para compreender a visão de Krasner (1985) sobre regimes internacionais. Os princípios e as normas fornecem as características essenciais que definem um regime. Já as regras e procedimentos de tomada de decisão são elementos decorrentes dos princípios e normas definidores de um regime. Assim, as mudanças em princípios e normas são mudanças do próprio regime, ou seja, ocorrendo uma mudança desse tipo, verifica-se a adoção de um novo regime. Por conseguinte, mudanças em regras e procedimentos de tomada de decisão são mudanças internas aos regimes, não havendo alterações nos princípios e nas normas definidoras dos regimes (KRASNER, 1985).

Portanto, Krasner (1982) define regimes internacionais como o conjunto de princípios, regras e procedimentos para tomada de decisões que reúnem uma convergência de expectativas dos atores internacionais em relação a uma determinada área de interesse e, em consequência, que regulam a atuação dos agentes internacionais 
e constrangem os seus comportamentos. Os regimes têm a função de facilitar a elaboração de acordos que condizem com os interesses dos Estados com o intuito de obter vantagens mútuas para as partes negociantes. Os regimes internacionais podem tratar de uma diversidade de questões e áreas, como economia, armas nucleares, meio ambiente, direitos humanos, entre outros, e a efetividade desses regimes varia de acordo com suas áreas temáticas e com o contexto no qual foram instituídos.

Em linhas gerais, os regimes internacionais têm por escopo a formação de normas e regras que garantam o funcionamento do sistema internacional anárquico. Diferentemente dos teóricos realistas, os teóricos que defendem a existência dos regimes não acreditam que as regras aplicáveis ao sistema internacional emergem das características estruturais inerentes ao próprio sistema.

Para eles, as normas e regras dos regimes são marcadas pela ausência de hierárquica e de mecanismos sancionadores. Além disso, a teoria de regimes se refere a padrões de comportamentos em referentes a determinadas áreas, ou seja, trata-se da lógica da repetição de jogos que cria uma estabilidade de expectativas em relação ao comportamento dos Estados, gerando informações, redução de custos de cooperação e permitindo que eles produzam comportamentos cooperativos, mesmo inseridos em um sistema anárquico (HERTZ, 1997).

\section{A CONSTRUÇÃO DO REGIME INTERNACIONAL DE PROTEÇÃO AOS DIREITOS HUMANOS}

O primeiro delineamento do processo de construção de um regime internacional de direitos humanos ocorreu com a instituição da Liga das Nações e da Organização Internacional do Trabalho, em 1919, por meio do Tratado de Versalhes, após o fim da Primeira Guerra Mundial. A partir desses acontecimentos, foi preciso flexibilizar o conceito de soberania para permitir a inserção dos direitos humanos internacionais no ordenamento jurídico e nas políticas dos Estados.

A consolidação desse regime internacional de direitos humanos começou a partir do momento pós Segunda Guerra Mundial, com a criação da Organização das Nações Unidas e assinatura da Carta das Nações Unidas em 1945, devido a necessidade de 
restaurar a proteção aos indivíduos em virtude das atrocidades e das violações dos direitos fundamentais vistas no conflito.

Em 1948, a Organização das Nações Unidas elaborou a Declaração Universal dos Direitos Humanos, documento que rege a atuação dos Estados quanto à proteção e o respeito à dignidade do ser humano em termos gerais. Ambos os documentos eram fundados nesse princípio e tinham intenções de estabelecer um ideal comum a ser perseguido e atingido por todos os povos e nações (ALVES, 1994).

Com a Declaração Universal dos Direitos Humanos de 1948, o tema dos direitos humanos passaram a integrar o domínio das relações internacionais, deixando de ser mantido como assunto interno de cada Estado. A partir de então, todo o sistema westfaliano, que tinha como atores exclusivos os Estados soberanos, foi modificado e passou-se a conferir à pessoa física a qualidade de sujeito dos direitos internacionais (ALVES, 2005).

Nesse cenário, a Declaração de 1948 foi o primeiro passo para a elaboração de outros instrumentos de direitos humanos no plano internacional e inaugurou o surgimento de um sistema global de proteção aos direitos humanos. Esse sistema foi ampliado pelo advento de diversos tratados internacionais com temas específicos como proteção ao meio ambiente, direitos das mulheres, direitos das crianças, tortura, discriminação racial, entre outros, visando garantir o exercício de liberdades individuais e a proteção de direitos humanos fundamentais em detrimento dos interesses individuais dos Estados nacionais (PIOVESAN, 2015).

Moravcsik (2000), ao tratar do regime internacional de direitos humanos, afirma que ele difere da maioria das outras formas de institucionalização de regimes internacionais. De acordo com o entendimento desse autor, as instituições internacionais que regulam questões monetárias, comerciais, ambientais, políticas de segurança, entre outras questões, são desenhadas para regular a política externa, enquanto as instituições internacionais de direitos humanos se voltam para atividades internas dos Estados que, de forma geral, não são garantidas por falhas das ações interestatais.

Essa crítica argumenta que o motivo que leva alguns países a aderirem e cumprirem, mesmo sem coerção, os dispositivos de alguns atos internacionais de que são signatários, mas que não geram obrigações recíprocas, é pensar que essas regras de 
direitos humanos são compatíveis com seus ideais democráticos e reforçam as suas instituições e políticas internas e, consequentemente, suas políticas públicas externas (MORAVCSIK, 2000).

Muito embora a proteção de direitos individuais não possa ficar alheia aos interesses e ao papel dos Estados nacionais, haja vista a importância destes em garantir esses direitos para os seus cidadãos, é possível estabelecer o equilíbrio entre esses elementos através dos regimes internacionais, especialmente, dos regimes de direitos humanos, que são capazes de arquitetar mecanismos que podem assegurar a proteção das pessoas, permitir um desenvolvimento mais equitativo e superar vulnerabilidades (ARAVENA, 2001).

\section{A CONSTRUÇÃO DO REGIME INTERNACIONAL DE PROTEÇÃO AOS DIREITOS HUMANOS DAS MULHERES E O TRÁFICO INTERNACIONAL DE PESSOAS}

A primeira fase da construção de um sistema de proteção dos direitos humanos foi marcada pela perspectiva da proteção geral, que trabalhava a questão da diferença, das desigualdades por questões étnicas, religiosas e sociais com base na igualdade não substancial, em virtude das heranças deixadas pelos regimes do nazismo e do fascismo no período da Segunda Guerra Mundial. A Declaração Universal de 1948 expressa essa ideia de forma clara, bem como a Convenção para a Prevenção e Repressão ao Crime de Genocídio, também de 1948 (PIOVESAN, 2003).

Esses documentos internacionais de tutela dos direitos humanos apresentam uma linguagem eminentemente universalista. Ao adotarem expressões como "ninguém" e "todos", deixam transparecer que têm por escopo assegurar a proteção universal dos direitos e garantias fundamentais. Assim, não existem concessões a esse preceito que levem em consideração as singularidades culturais quando há risco de violação da dignidade humana, ainda que o direito de exercer a própria cultura seja também um direito protegido pela Declaração Universal dos Direitos Humanos.

Assim, a abrangência, a validação e a legitimidade das normas jurídicas elaboradas a partir dessa concepção reducionista passaram a ser questionadas, pois poderiam ocasionar a não eficiência das mesmas em uma ótica global. Essas normas, 
então, deveriam considerar diferentes culturas e não se sobreporem uma a outra (TRINDADE, 1997).

Dessa forma, ser universal em meio a tanta diversidade tornou-se o grande desafio do Direito Internacional dos Direitos Humanos, especialmente quando atitudes no âmbito doméstico, que são adotadas de acordo com práticas e costumes locais já consolidados, ganham repercussão global por serem consideradas violações graves de direitos humanos (RAMOS, 2012).

No entendimento de Boaventura de Sousa Santos (1997), é imprescindível levar em consideração os pormenores de cada Estado criando alternativas às imposições hegemônicas para não haver dificuldades na implementação e prática dos direitos humanos. Para tanto, propõe a aplicação do multiculturalismo articulando o princípio da igualdade com o do reconhecimento das diferenças para dar efetividade aos direitos humanos sem hegemonização.

Portanto, tratar o indivíduo de forma genérica e abstrata, como na Declaração de 1948, era insuficiente, por que vários grupos sociais deixaram de ser protegidos de forma devida. Neste sentido, percebeu - se que determinados sujeitos de direitos, ou determinadas violações de direitos, exigiam uma resposta específica e diferenciada, obtida através da modificação do foco de proteção. Fez-se necessária a especificação do sujeito de direito, que passou a ser considerado em suas particularidades.

Esse processo de especificação significa que os direitos humanos, apesar de universais, são usufruídos e exercidos de maneiras diferentes, de acordo com as características próprias de cada indivíduo, incluindo o gênero, a raça, a etnia, a situação econômica, o contexto sócio político e também a influência exercida por padrões culturais definidos pela comunidade ou país em que os indivíduos estão inseridos (GONÇALVES, 2013).

Nesse contexto, insere-se o reconhecimento dos direitos humanos das mulheres. Durante a II Conferência Internacional sobre os Direitos Humanos, por intermédio da Declaração e o Programa de Ação de Viena, foi reconhecido, pela primeira vez em um documento internacional, que o Estado tem o dever de eliminar a violência baseada no gênero e todas as formas de abuso e exploração sexual. É importante ressaltar que a 
declaração enuncia expressamente que os direitos humanos da mulher e da menina constituem parte inalienável, integral e indivisível dos direitos humanos universais.

Em relação à violência de gênero e ao tráfico internacional de mulheres na Declaração de Viena, ressaltou-se a importância de os países trabalharem de forma coordenada, contando também com a participação da sociedade civil, no intuito de eliminar esse tipo de violência (JESUS, 2003).

Ainda em relação ao tráfico internacional de pessoas, o artigo 18 da Declaração de Viena, dedicado à proteção dos direitos das mulheres, aduziu que todas as formas de assédio, violência de gênero e exploração sexual, inclusive as resultantes de preconceito cultural e o tráfico internacional de pessoas, são incompatíveis com a dignidade e o valor da pessoa humana e devem ser eliminados.

Em 1995, na Conferência de Pequim sobre os Direitos das Mulheres, traçou-se um panorama mundial abordando a questão da mulher e elaborou políticas específicas a serem seguidas pelos Estados. Trata -se do documento internacional mais completo no tocante a esta questão, haja vista que identificou os principais problemas relacionados à violação dos direitos das mulheres.

Esse documento foi a Declaração de Pequim que, assim como a de Viena, dedicouse de forma especial à temática da violência contra a mulher, na qual se inseriu à questão do tráfico internacional de mulheres. Esta Declaração alterou o tratamento dado à questão da criminalização do ato de prostituição, presente nos tratados antitráfico desde a Convenção de 1949. Para isso, utilizou a conceituação de prostituição forçada como uma violência contra a mulher, entendendo que a prostituição livre era vista como uma prática que não violaria os direitos das mulheres (CASTILHO, 2008).

O Estatuto do Tribunal Penal Internacional definiu, em 1998, a escravidão sexual, a prostituição forçada ou qualquer outro tipo de violência de cunho sexual como crimes contra a humanidade. O Tribunal Penal internacional (TPI) é o órgão jurisdicional internacional responsável por processar e julgar os crimes mais graves que afetam a comunidade internacional. Esse instrumento traz o seguinte conceito de escravidão sexual: exercer um dos atributos do direito de propriedade sobre uma pessoa, tal como comprar, vender, dar em troca ou impor alguma privação ou qualquer outra forma de reduzir alguém à condição análoga à escravidão (BRANT; STEINER, 2016). 
Também em 1998, o Brasil ratificou a Convenção Interamericana sobre Tráfico Internacional de Menores ${ }^{3}$, que conceituou o tráfico internacional de pessoas menores de dezoito anos como a subtração, transferência ou retenção, ou a tentativa de subtração, transferência ou retenção de um menor, com propósitos ou por meios ilícitos. Como exemplos de propósitos ilícitos, a Convenção trouxe a prostituição, a exploração sexual, e a servidão e elenca como meios ilícitos, o sequestro, o consentimento mediante coerção ou fraude, a entrega ou recebimento de pagamentos ou benefícios ilícitos com vistas a obter o consentimento dos pais, das pessoas ou da instituição responsáveis pelo menor (KAMIMURA; PIOVESAN, 2013).

A Assembleia Geral da ONU criou um comitê intergovernamental para elaborar uma Convenção Internacional abordando a criminalidade organizada transnacional e também para examinar a possibilidade de elaborar um instrumento que tratasse de todos os aspectos relativos ao tráfico internacional de pessoas, em especial de mulheres e de crianças. O comitê, em 1999, apresentou uma proposta de instrumento que, no ano seguinte, foi aprovada como Convenção das Nações Unidas contra o Crime Organizado Transnacional (CASTILHO, 2008).

A realização de conferências internacionais e a assinatura de tratados, acordos, protocolos ou convenções, criaram um importante sistema de apoio para confrontar o problema das desigualdades de gênero, nos países desenvolvidos e em desenvolvimento, ao passo que definiram a natureza e o rol de problemas que afetam as mulheres e propiciaram subsídios para a sua proteção em diferentes níveis e para a elaboração de políticas públicas mais específicas (EPPING; PRÁ, 2011).

Dessa forma, os esforços multilaterais de proteção dos direitos humanos, ocorridos na década de 90 e nos anos 2000, referentes ao tráfico de pessoas, evidenciam o crescimento da atenção da comunidade internacional no que concerne aos direitos humanos das mulheres e do mencionado tema.

Esses documentos internacionais revelaram-se, tanto na ordem internacional como na ceara nacional, instrumentos políticos promotores de avanços sociais na medida

\footnotetext{
${ }^{3}$ BRASIL. Decreto n 2.740, de 20 de agosto de 1998. Promulga a Convenção Interamericana sobre Tráfico Internacional de Menores, assinada na Cidade do México em 18 de março de 1994. Diário Oficial da União, Brasília, DF, 21 ago. 1998.
} 
em que atuam como mecanismos de conscientização para a sociedade e de compromisso por parte dos Estados.

\section{O BRASIL E O REGIME INTERNACIONAL DE PROTEÇÃO AOS DIREITOS HUMANOS}

A Declaração Universal de Direitos Humanos da ONU foi um instrumento político de fundamental importância, por que introduziu intensas modificações sociais, políticas e econômicas na ordem internacional e na ordem doméstica de muitos Estados. Pode-se pensar na Declaração como o princípio de muitos outros compromissos de proteção aos direitos humanos que foram assumidos pelos Estados nacionais ao longo dos anos. Atualmente, todos os acordos internacionais firmados pelo Brasil, têm sido constantemente utilizados como fontes de conscientização dos cidadãos, além de referências para a adoção de medidas políticas, leis e programas sociais que visem à proteção dos direitos humanos (ALVES, 2009).

Esse fato é perceptível através da análise comparativa entre garantias civis e sociais estabelecidas na Constituição Brasileira de 1946, a última promulgada antes do advento da Declaração dos Direitos Humanos da ONU, e as garantias firmadas na Carta Magna de 1988, hoje em vigor. Ressalvado o período da história do Brasil dominado pela ditadura militar (1964 - 1985), em que a participação do Brasil no cenário internacional foi motivada pela necessidade de melhorar a sua imagem diante de tantas violações de direitos que aqui ocorreram, muitos avanços foram conquistados a partir da instauração da nova ordem mundial do momento pós Segunda Guerra.

Um ano antes do início do período de redemocratização, em 1984, o Brasil deu o primeiro passo no processo de incorporação do regime internacional de direitos humanos em sua agenda política, com a ratificação da Convenção sobre a Eliminação de todas as formas de Discriminação contra a Mulher e consequente inserção desse instrumento no ordenamento jurídico pátrio. Antes desse episódio, em 1968, o Brasil havia ratificado um outro tratado internacional, a Convenção sobre a Eliminação de todas as formas de Discriminação Racial, mas tratou -se de um ato isolado, apesar de ter grande importância para a proteção aos direitos humanos (PIOVESAN, 2015). 
O processo de redemocratização no Brasil teve início no ano de 1985 e foi muito importante para promover transformações na agenda internacional do país, especialmente conferindo maior reconhecimento de obrigações internacionais em matéria de Direitos Humanos. Outro acontecimento relevante foi o crescimento da mobilização da sociedade civil e das organizações não governamentais trazendo o discurso de proteção aos direitos humanos (PIOVESAN, 2015).

O episódio histórico de maior relevância nessa conjuntura foi a promulgação da Constituição Federal de 1988. As regras constitucionais dessa carta foram deveras influenciadas por normas e preceitos consolidados nas Nações Unidas e nos tratados internacionais existentes até então, principalmente no tocante aos direitos humanos, ratificando a intolerância às violações desses direitos (PIOVESAN, 2015).

Durante a década de 1990, o Brasil fortaleceu a adesão ao sistema internacional de proteção aos diretos humanos, ratificando um grande número de tratados, pactos e convenções internacionais importantes. Com essa inclusão de instrumentos internacionais de direitos humanos no ordenamento jurídico pátrio, o Brasil passa a ter compromissos internacionais como a promoção e a proteção dos direitos de diversos segmentos sociais, a apresentação de relatórios periódicos aos comitês que supervisionam a execução de cada um dos grandes atos internacionais de direitos humanos, o fortalecimento de sua política externa no que concerne ao tema, a criação de uma estrutura política e social para promover esses direitos internamente, entre outros. Nessa perspectiva, o Brasil, consequentemente, passa a ser cobrado e fiscalizado no cumprimento dessas novas obrigações e mostra-se como país respeitador e garantidor de direitos humanos (ALVES, 2008).

O Brasil, portanto, se comprometeu perante a comunidade internacional a manter e desenvolver o Estado Democrático de Direito e a proteger um conjunto de direitos inalienáveis, irrenunciáveis e invioláveis que, por sua própria natureza, de acordo com Flávia Piovesan (2015) ampliam o significado do termo "cidadania”, visto que, além dos direitos já previstos na Constituição Federal, os cidadãos brasileiros passaram a ser titulares de direitos internacionais.

O país prossegue inserido e atuante no regime internacional de direitos humanos, com a apresentação de relatórios nacionais aos órgãos de supervisão dos instrumentos internacionais de direitos humanos, participação mais direta em diversos órgãos de 
implementação e controle das recomendações e normas internacionais, com maior representatividade em grupos da $\mathrm{ONU}$, assumindo outras responsabilidades em órgãos internacionais como a Organização dos Estados Americanos (OEA).

Não obstante, ainda que exista esse avanço significativo, existem tratados aguardando ratificação e outros que, apesar de ratificados, não possuem vigência plena devido ao grande número de reservas e declarações restritivas feitas pelo Brasil no momento da ratificação. Posto isto, é necessário que o Brasil considere reavaliar sua posição frente aos procedimentos facultativos trazidos no bojo desses tratados e também fazer as modificações na legislação interna, afim de adequá-la aos ditames dos tratados para sua plena inserção no sistema internacional de proteção dos direitos humanos (PIOVENSAN, 2015).

Os próximos pontos a serem abordados nesse artigo trarão uma exposição pormenorizada a respeito da inserção do Brasil no regime internacional de direitos humanos a partir da análise dos instrumentos internacionais que trazem como tema principal a proteção internacional dos direitos humanos das mulheres e o tráfico de pessoas.

\section{PRINCIPAIS INSTRUMENTOS INTERNACIONAIS}

\subsection{A CONVENÇÃ̃ SOBRE A ELIMINAÇÃO DE TODAS AS FORMAS DE DISCRIMINAÇÃO CONTRA A MULHER}

Como primeiro marco legal internacional do reconhecimento dos direitos humanos das mulheres, a Assembleia Geral das Nações Unidas trouxe a Convenção para a Eliminação de Todas as Formas de Discriminação contra a Mulher ou Convention on the Elimination of All Forms of Discrimination against Women (CEDAW) ${ }^{4}$, aprovada em 18/01/1979, pela Resolução nº. 34/180 da Assembleia Geral da ONU, tendo entrado em

\footnotetext{
${ }^{4}$ ORGANIZAÇÃO DAS NAÇÕES UNIDAS. Convention on the Elimination of All Forms of Discrimination against Women. Disponível em: https://treaties.un.org/pages/ViewDetails.aspx?src=IND\&mtdsg no=IV8\&chapter $=4 \&$ clang= en . Acesso em 12.10.2016.
} 
vigor em 03/09/1981. Hoje, ela conta com a adesão de 189 Estados - Parte. “Todos os países da América Latina ratificaram a Convenção, embora com reservas, inclusive o Brasil, que a ratificou em 1984 e somente suspendeu as reservas em 1994." (JESUS, 2003, p. 33).

Essa Convenção foi idealizada anos antes de ter sido efetivamente elaborada, em 1946, quando foi instituída a Commission on the Status of Women (CSW) ou Comissão sobre o Status da Mulher pela Assembleia Geral da ONU, com o objetivo de criar recomendações que oferecessem um aparato teórico e prático para que os Estados elaborassem políticas públicas para o desenvolvimento das mulheres.

A Convenção para a Eliminação de Todas as Formas de Discriminação contra a Mulher é o único tratado internacional que trata de maneira ampla dos direitos das mulheres. Trata-se de uma carta de direitos que compreende direitos civis, políticos, econômicos, sociais e culturais. No seu artigo $1^{\stackrel{o}{0}}$, esse documento define que a discriminação contra a mulher é entendida como qualquer distinção, exclusão ou restrição baseada no sexo que tenha por escopo anular o reconhecimento, o gozo ou o exercício de seus direitos humanos ou liberdades fundamentais.

Ela possui artigos que enunciam direitos relacionados à saúde, vida econômica e social e relações familiares, considerando a situação de desigualdade entre homens e mulheres e sua situação de vulnerabilidade social, bem como artigos que regulamentam a atuação do Comitê sobre a Eliminação da Discriminação contra as Mulheres ou Comitê da CEDAW, composto por especialistas eleitos pelos Estados-Parte, responsável por monitorar e implementar os ditames da Convenção.

Entretanto, vários países que ratificaram essa Convenção, o fizeram com reservas a alguns de seus dispositivos, o que dificulta a sua aplicação já que os Estados - parte não se obrigam a garantir esses direitos em seu âmbito doméstico. 0 Comitê possui também a função de encorajar os países a retirarem as reservas para evitar a redução da força do tratado (GONÇALVES, 2013).

Embora a CEDAW tenha sido de fundamental importância para a especificação dos direitos humanos das mulheres, ela não abordou de forma explícita a temática da violência contra a mulher. Esse tema foi trabalhado na Recomendação Geral no 19 adotada em 1992 pelo Comitê da CEDAW, que declara ser a violência contra as mulheres uma 
forma aguda de discriminação, que as impede de usufruírem de seus direitos e liberdades de forma equânime em relação aos homens. A Recomendação Geral também impõe aos Estados-parte a obrigação de promover a melhoria das condições de vida de mulheres e meninas, assegurando-lhes todos os seus direitos fundamentais e uma vida livre de violência e de discriminação.

A CEDAW trouxe um grande avanço no que concerne aos direitos humanos das mulheres, o que culminou em muitas transformações sociais nos Estados - Parte e, consequentemente, mudanças ocorridas no cenário internacional. Contudo, sabe-se que mesmo com a existência de instrumentos internacionais de direitos humanos, a mulher ainda é alvo de discriminação e de violações de direitos e esse fato é um entrave para a consolidação da participação das mulheres, em mesmo nível de igualdade com os homens, nas esferas política, social, econômica e cultural.

\subsection{A CONVENÇÃO INTERAMERICANA PARA PREVENIR, PUNIR E ERRADICAR A VIOLÊNCIA CONTRA A MULHER}

A Convenção Interamericana para Prevenir, Punir e Erradicar a Violência contra a Mulher, também conhecida como Convenção de Belém do Pará, foi adotada pela Assembleia Geral da Organização dos Estados Americanos em 6 de junho de 1994 e ratificada pelo Brasil em 27 de novembro de 1995. Este tratado traz maior visibilidade ao tema da violência contra a mulher, regulamentando a sua proibição no âmbito regional, abordando a violência no âmbito privado e a questão da violência doméstica, assegurando às mulheres diversos direitos e liberdades e impondo obrigações aos Estados-parte.

A questão da violência de gênero já vinha sendo discutida em foros internacionais antes desse tratado ser elaborado. Em 1993, a Assembleia Geral das Nações Unidas aprovou a Declaração sobre a Eliminação da Violência contra Mulher, por exemplo. Embora tenha sido o primeiro documento internacional que trata somente sobre este tema, ele não era juridicamente vinculante em relação aos Estados, ou seja, não cria obrigações pelas quais possam ser sancionados em caso de descumprimento.

Apesar de a Convenção de Belém do Pará ter sido aprovada em âmbito regional, seu texto foi inovador, muito relevante para o reconhecimento e proteção dos direitos 
humanos das mulheres ao tratar, em especial, da violência contra a mulher como grave violação a esses direitos e às liberdades fundamentais, impondo aos Estados-Parte o dever de investigar e condenar todas as formas de violência contra a mulher (nos âmbitos público e privado) e adotar políticas orientadas a prevenir, punir e erradicar esta violência, bem como agir no sentido de fornecer as vítimas acesso a procedimentos jurídicos eficazes.

O Sistema Interamericano de Direitos Humanos possui uma Relatoria Especial para assuntos relacionados aos direitos das mulheres, a "Relatoría sobre los Derechos de La Mujer", ligada à Comissão Interamericana de Direitos Humanos. Essa relatoria tem desempenhado um importante papel como órgão responsável por organizar, sistematizar e divulgar informações sobre a situação das mulheres nas Américas, contribuindo assim, por meio de seus informes, para dar visibilidade aos problemas das mulheres na região, bem como para apontar propostas de soluções para esses problemas (GONÇALVES, 2013).

Os artigos $1^{\mathrm{o}}$ e $2^{\mathrm{o}}$ da Convenção trazem a definição de violência de gênero de forma ampla e destacam que existem vários tipos de violência contra a mulher: a violência física, a violência sexual e a violência psicológica. Esses artigos ainda afirmam que esses atos de violência podem acontecer dentro do ambiente familiar ou em qualquer outro ambiente, inclusive podendo ser praticados pelo Estado ou por qualquer um de seus agentes.

Os artigos $3^{\circ}$ a $6^{\circ}$ trazem exemplos de direitos das mulheres que devem ser garantidos, demonstrando o reconhecimento de sua situação de vulnerabilidade e necessidade de se garantir a sua dignidade humana. Entre eles, temos o direito à integridade física, mental e psicológica, o direito à liberdade, o direito de não ser submetida à tortura, o direito à segurança, o direito a uma vida livre e sem violência, o direito de ser valorizada e educada livre de padrões de comportamento ou práticas sociais que as inferiorizem.

Os artigos 7ํㅜ a 9o da Convenção trazem os deveres dos Estados-Parte. Os principais compromissos acordados pelos Estados nessa Convenção são: incluírem em suas legislações internas normas penais, civis e administrativas necessárias para prevenir, punir e erradicar a violência contra a mulher; tomarem todas as medidas apropriadas, incluindo medidas legislativas, para modificar ou revogar lei e regulamentos 
vigentes, ou para modificar práticas jurídicas ou consuetudinárias que respaldem a tolerância da violência contra a mulher; e estabelecerem um atendimento jurídico eficaz e justo para mulheres vítimas de violência.

Os artigos 10 a 12 trazem os mecanismos de proteção aos direitos das mulheres estabelecidos pelo Sistema Interamericana de Direitos Humanos. 0 artigo 12, especificamente, com o propósito de proteger o direito da mulher a uma vida livre de violência, autoriza qualquer pessoa, grupo de pessoas ou entidade não-governamental legalmente reconhecida em um ou mais Estados membros da Organização, a apresentar à Comissão Interamericana de Direitos Humanos petições que contenham denúncias ou queixas de violações dos deveres postulados no artigo $7^{\circ}$ da Convenção cometidas pelos Estados.

\subsection{A CONVENÇÃO DAS NAÇõES UNIDAS CONTRA O CRIME ORGANIZADO TRANSNACIONAL E O PROTOCOLO DE PALERMO}

No contexto do surgimento desses importantes tratados internacionais voltados para a proteção dos direitos humanos, merece destaque a Convenção das Nações Unidas contra o Crime Organizado Transnacional e seus respectivos Protocolos Adicionais, haja vista que tais documentos tratam especificamente do tráfico internacional de pessoas. Essa Convenção representa a tentativa de unificar ideias presentes em tratados internacionais anteriores que abordavam aspectos do crime organizado transnacional.

De forma detalhada, esse instrumento internacional procurou atingir um universo bastante amplo de possibilidades de atuação criminosa, de meios utilizados para a consecução do crime e de formas de exploração decorrentes do delito, tudo no sentido de fortalecer os eixos do enfrentamento compreendidos na prevenção, repressão e responsabilização dos autores e favorecer a proteção da vítima, no caso do tráfico, considerando as múltiplas peculiaridades do delito que o torna bastante difícil de combater.

Portanto, a Convenção de Palermo e seus respectivos protocolos trazem orientações para que os Estados - Partes implementem o controle do crime organizado transnacional, pautando as suas ações na prevenção, investigação, instrução e julgamento 
dos crimes tipificados nesse dispositivo. Essas ações consistem em cooperação internacional com organizações internacionais e outros Estados, aplicação da lei, promulgação de leis específicas, maior fiscalização e proteção das fronteiras pelas autoridades policiais e proteção às vítimas (JESUS, 2003).

O Protocolo Adicional à Convenção das Nações Unidas contra o Crime Organizado Transnacional Relativo à Prevenção, Repressão e Punição do Tráfico de Pessoas, em Especial Mulheres e Crianças, conhecido como Protocolo de Palermo, é o instrumento internacional que cuida do enfrentamento ao tráfico internacional de pessoas.

Após uma série de discussões no âmbito internacional e debates sobre o tema na academia, movimentos sociais e órgãos da esfera pública, o Protocolo de Palermo entrou em vigor substituindo a Convenção das Nações Unidas sobre Supressão do Tráfico de Pessoas e a Exploração da Prostituição de Outros de 1949. Essa norma representou um avanço para a época, mas manteve a associação do tráfico de pessoas com a prostituição, entendendo esta como uma prática a ser proibida em qualquer de suas formas, ainda que exercida por pessoas adultas e ainda que não fosse praticada de forma forçada. Diferentemente, o Protocolo de Palermo não aborda o tráfico de maneira associada à prostituição, além de distinguir, por via interpretativa, a prostituição forçada da prostituição exercida livremente (OLIVEIRA; SCHILLING, 2014).

Durante o processo de negociação, muitas entidades protetoras dos direitos humanos estavam presentes e foram de fundamental importância para a inclusão de aspectos de direitos humanos no Protocolo. Assim, o tráfico internacional de pessoas, além de ser considerado um crime transnacional grave, também é considerado como uma flagrante violação de direitos humanos fundamentais. Essa perspectiva melhorou as recomendações de tratamento das pessoas traficadas, promovendo maior respeitabilidade aos direitos das vítimas.

Com a ratificação do tratado, o Brasil assumiu o compromisso de se estruturar, criando instrumentos legais e mecanismos políticos e administrativos para promover enfrentamento ao tráfico internacional de pessoas, sob pena de ser responsabilizado internacionalmente, e também assume o compromisso de prestar devida assistência às vítimas de tráfico com total respeito aos direitos humanos. 
O Protocolo de Palermo traz a exploração como o elemento principal utilizado na construção do conceito de tráfico internacional de pessoas. Essa exploração pode estar associada ao comércio sexual ou prostituição, ao trabalho escravo ou práticas análogas e a remoção de órgãos.

Nesse sentido, busca disciplinar ações e medidas destinadas a prevenir e combater o tráfico internacional de pessoas, conferindo especial atenção às mulheres e crianças, sempre pautadas com a plena garantia de seus direitos humanos. Para garantir o alcance desse objetivo principal, recomenda a cooperação entre os Estados- Partes, diante da gravidade e do caráter transnacional do crime.

Essa cooperação consiste na troca de informações entre as autoridades judiciais e administrativas dos Estados envolvidos, solicitação de diligências, produção de atos processuais e de troca de provas com o objetivo de promover uma investigação mais coerente de crimes transnacionais e, consequentemente, subsidiar a comprovação dessas práticas criminosas (MINISTÉRIO PÚBLICO FEDERAL, 2015).

Apesar de a cooperação internacional ser a medida recomendada pelo Protocolo de Palermo, é interessante destacar que a cooperação, bem como outras recomendações, não podem ser exercidas de maneira uniforme por todos os países membros, pois estão sujeitas as contradições e posições assimétricas dos Estados no cenário internacional. Tais assimetrias refletem diretamente na classificação e enquadramento conceitual e jurídico de quem é considerada vítima ou não, nas decisões judiciais relacionadas ao delito, no modo como o tema é tratado pelos meios de comunicação e pela sociedade civil e, especialmente, repercutem na elaboração e execução da política externa de enfrentamento.

A análise das causas e consequências nos casos envolvendo tráfico internacional de pessoas deve perpassar por questões sociais, econômicas, políticas e culturais dos Estados envolvidos. Conciliando esses fatores com os princípios fundamentais que regem os direitos humanos, existe maior possibilidade de definir estratégias de prevenção e combate ao tráfico e também de prestar melhor assistência às vítimas (JESUS, 2003).

\section{CONSIDERAÇÕES FINAIS}


A partir da análise dos aspectos teóricos pertinentes aos regimes internacionais e, em específico, ao regime internacional dos direitos humanos, tal como do comportamento do Brasil nesse regime, é possível inferir que nosso país tem dado importância à questão do enfrentamento as violações dos direitos humanos das mulheres através da construção de sistema de apoio para confrontar problemas relacionados às desigualdades de gênero.

Nesse sentido, o presente artigo procurou destacar o papel dos instrumentos internacionais que tratam da defesa dos direitos das mulheres e do tráfico internacional de pessoas como elementos principais desse sistema e demonstrar que a adesão do Brasil a esses tratados evidencia a transformação do enfrentamento ao tráfico internacional de mulheres em uma importante prioridade política.

O Brasil se apresenta como um país que respeita os direitos humanos e possui participação efetiva em foros multilaterais, bem como elabora estudos e pesquisas antitráfico e possui ações correlatas aos regimes internacionais de combate a esse ato ilícito. A entrada em vigor do Protocolo de Palermo obedece a tendência de criação de tratados para proteger sujeitos específicos. A partir de sua promulgação, o debate internacional sobre tráfico de mulheres se intensificou de maneira notável, evidenciando que o tema não se apresenta esquecido e negligenciado pelos órgãos de defesa dos direitos humanos, em nível internacional e nacional.

Não obstante os avanços obtidos na esfera constitucional e internacional, reforçados, ainda, pelo advento de leis infraconstitucionais, refletindo as reivindicações e anseios das mulheres, ainda persiste na cultura brasileira uma ótica sexista, discriminações com relação à mulher e violações de seus direitos humanos. Logo, os ganhos internacionais e constitucionais legais de forma isolada não geram automaticamente mudanças sociais e culturais, apesar de denotarem maior segurança para os sujeitos de direito.

\section{REFERÊNCIAS}

ALVES, José Augusto Lindgren. A Declaração Universal dos Direitos Humanos no Discurso Diplomático Brasileiro. In: 60 anos da Declaração Universal dos Direitos Humanos: conquistas do Brasil. Org. Andrea Giovannetti. Brasília. Fundação Alexandre de Gusmão, 2009, p. 63-96. 
Os direitos humanos como tema global. São Paulo: Perspectiva; Brasília, DF: Alexandre de Gusmão, 1994.

Direitos Humanos e o papel do Brasil. In: O Brasil e a ONU. Org. Organização das Nações Unidas. Brasília: Fundação Alexandre de Gusmão, 2008.

. Os Direitos Humanos na Pós-Modernidade. São Paulo: Perspectiva, 2005.

ARAVENA, Francisco Rojas. Seguridad humana: concepto emergente de la seguridad del siglo XXI. In: Seguridad humana, prevención de conflictos y paz en America Latina e Caribe. UNESCO e FLASCO-Chile (org.). Santiago: novembro, 2001.

BRASIL. Decreto $n^{\circ}$ 2.740, de 20 de agosto de 1998. Promulga a Convenção Interamericana sobre Tráfico Internacional de Menores, assinada na Cidade do México em 18 de março de 1994. Diário Oficial da União, Brasília, DF, 21 ago. 1998.

BRASIL. Decreto $n^{\circ}$ 5.017, de 12 de março de 2004. Promulga o Protocolo Adicional à Convenção das Nações Unidas contra o Crime Organizado Transnacional Relativo à Prevenção, Repressão e Punição do Tráfico de Pessoas, em Especial Mulheres e Crianças. Diário Oficial da União, Brasília, DF, 15 mar. 2004.

CASTILHO, Ela Wiecko Volkmer de. Tráfico de pessoas: da Convenção de Genebra ao Protocolo de Palermo. In: BRASIL. SECRETARIA NACIONAL DE JUSTIÇA. Política nacional de enfrentamento ao tráfico de pessoas. Brasília-DF, SNJ, 2008.

EPPING, Léa; PRÁ, Jussara Reis. Cidadania e Feminismo no reconhecimento dos Direitos Humanos das mulheres. Revista Estudos Feministas, v.20, p.33-51, jan-abr. 2012.

GONÇALVES, Tamara Amoroso. Direitos Humanos das Mulheres e a Comissão Interamericana de Direitos Humanos. 1aed. São Paulo: Saraiva, 2013.

HERZ, Mônica. Teoria das Relações Internacionais no Pós-Guerra Fria. Dados - Revista de Ciências Sociais. Rio de Janeiro, v. 40, n. 2, p., 1997. Disponível em: http://www.scielo.br/scielo.php?script=sci arttext\&pid=S0011-

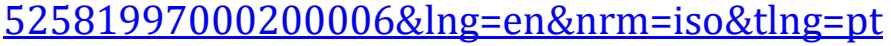

JESUS, Damásio de. Tráfico internacional de mulheres e crianças - Brasil: aspectos regionais e nacionais. São Paulo: Saraiva, 2003.

KAMIMURA, Akemi; PIOVESAN, Flávia. Tráfico de Pessoas sob a Perspectiva de Direitos Humanos: Prevenção, Combate, Proteção às Vítimas e Cooperação Internacional. In: Tráfico de Pessoas: uma abordagem para os direitos humanos. Brasília: Ministério da Justiça, 2013.

KEOHANE, Robert Owen. After Hegemony: cooperation and discord under the world political economy. Princeton, NJ: Princeton University Press, 1984. Caps. 4 e 5.

KEOHANE, Robert Owen. International Institutions: Two Approaches. In: International Institutions and State Power: Essays in International Relations. Boulder: Westview Press, 1989. Cap. 7, p. 158-179.

KEOHANE, Robert Owen; NYE, Joseph Samuel. Power and Interdependece. $4^{\mathrm{a}}$ Ed. Editora Longman, 1977.

KRASNER, Stephen. Structural Causes and Regimes Consequences: Regimes as Intervening Variables, International Organization, v. 36, n‥ 1, pp. 185-206, 1982. 
KRASNER, Stephen. Causas estruturais e consequências dos regimes internacionais: regimes como variáveis intervenientes. Revista de Sociologia Política. Curitiba, v. 20, no․ 42, p. 93-110, jun./2012.

MINISTÉRIO PÚBLICO FEDERAL. Migração e Tráfico Internacional de Pessoas. Guia de referência para o Ministério Público Federal. Brasília: MPF, 2016.

MINISTÉRIO PÚBLICO FEDERAL. Temas de cooperação Internacional. Brasília: MPF, 2015.

MORAVCSIK, Andrew. The Origins of Human Rights Regimes: Democratic Delegation in Postwar Europe. In: International Organization. The IO Foundation and the Massachusetts Institute of Technology,v. 2, no54, 2000, p. 217-252.

BRANT, Leonardo Nemer Caldeira; STEINER, Sylvia Helena. O Tribunal Penal Internacional - Comentários ao Estatuto de Roma. 1a ed. Belo Horizonte: Editora Del Rey, 2016.

OLIVEIRA, Fernanda Castro Souza Fernandes; SCHILLING, Flávia Inês. Globalização, prostituição e tráfico de pessoas. Revista Communicare - Dossiê Feminino, v.14, p.46 - 58, jan/jun.2014.

ORGANIZAÇÃO DAS NAÇÕES UNIDAS. Convention on the Elimination of All Forms of Discrimination against Women. Disponível em: https://treaties.un.org/pages/ViewDetails.aspx?src=IND\&mtdsg no=IV8\&chapter=4\&cl ang= en. Acesso em:12.10.2016.

ORGANIZAÇÃO INTERNACIONAL DO TRABALHO (OIT). Aliança Global contra o trabalho forçado: relatório global do seguimento da Declaração da OIT sobre princípios e direitos fundamentais no trabalho, 2005.

PIOVESAN, Flávia. A mulher e o debate sobre Direitos Humanos no Brasil. In: Ministério das Relações Exteriores. Direitos Humanos: atualização do debate. Brasília: Bandeirantes, 2003, p. 39-44.

Saraiva, 2015.

Direitos Humanos e o Direito Constitucional Internacional. 14aㅡ ed. São Paulo:

RAMOS, André de Carvalho. Teoria geral dos direitos humanos na ordem internacional. Rio de Janeiro: Editora Renovar, 2012.

SANTOS, Boaventura de Sousa. Por uma concepção multicultural de direitos humanos. In: Revista Crítica de Ciências Sociais, p.11-32, jun.1997.

SOUZA, Mércia Cardoso de. A Convenção sobre a Eliminação de todas as Formas de Discriminação contra as Mulheres e suas Implicações para o Direito Brasileiro. Revista Eletrônica de Direito Internacional, v. 5, p.346-386, 2009.

TRINDADE, Antônio Augusto Cançado. Tratado de direito internacional de direitos humanos. v. 1. Porto Alegre: Sérgio Antônio Fabris, 1997.

UNITED NATIONS OFFICE ON DRUGS AND CRIME (UNODC). Global Report on Trafficking in Persons, 2016. 
USMAN, Mikail Usman. Trafficking in women and children as vulnerable groups: talking through theories of international relations. European Scientific Journal, v. 10, n. 17, 2014. 